\title{
A Sociolinguistic Study of Vowel Harmony in Persian: People with Different Gender Use of Vowel Harmony Perspective
}

\author{
Morad Bagherzadeh Kasmani
}

\begin{abstract}
The data of the present article was collected through a randomly classified data collection process and Labovian sociolinguistic interviews; the data, then, was analyzed through the Pearson Chi square method by means of SPSS. The data was described through cross tabulations and diagrams as well. In addition, the multivariate log linear has been conducted to determine which of the independent variables under study affects the use of vowel harmony more than the other, the gender or style. A total of 47 informants were interviewed: there are two groups of informants, 27 I.R.I.B. employees (15 male and 12 female) and 20 university students (10 male and 10 female). The subjects' speech has also been examined in different styles (Free Speech, Reading Sentences, Fast Word Reading and Slow Word Reading). The hypothesis of the present survey research is that there is a significant difference between and among different groups of informants' accents regarding their use of vowel harmony. The results of the study shows that female people tend to use more formal and more prestige variants than male ones leading to a change in language in general (and in the use of vowel harmony in particular).
\end{abstract}

Index Terms-Gender, vowel harmony, extra linguistic factors, prestige, formal.

\section{INTRODUCTION}

This survey research is an attempt to study vowel harmony in its social context considering the effects of gender on the use of vowel harmony in Persian. Thus, the present study which is a quantitive study of speech is concerned with analyzing sociolinguistic variation existing in the speech of subjects with different gender.

The point of view of the present study is that one can not understand the language fully apart from the social life of the community in which it occurs and that language is a socio-cultural phenomenon and context-dependent.

This study shows that the variation in the use of vowel harmony in Persian is not free; rather, it depends on the gender, formality or informality of the context, prestige and the frequency of occurrence of the linguistic element.

Furthermore, the study demonstrates that no change occurs in a social vacuum and before a phonetic variant can spread from word to word, it is necessary that one of the two rivals shall acquire some sort of prestige as it is the case for [p] in [nvhpr], the informal variant (lunch) versus [a] in [nahpr], the formal variant investigated in the present study.

Manuscript received September 21, 2013; revised November 27, 2013.

Morad Bagherzadeh Kasmani is with the Islamic Azad University, Chalous Branch (e-mail: kasmankola@yahoo.com).
Furthermore, it should be noted that vowel harmony (VH) operates left in Persian (e.g. /e/ in /be+bor/ changes into [o], $\mathrm{so} / \mathrm{be}+\mathrm{bor} /$ changes into [bobor]. Therefore, it is the vowel on the left syllable which is affected. Moreover, it is affected by word- boundaries and only is the vowel in the immediate left syllable affected by VH. For instance, if the vowel harmony applies on the sentence / \# ino (this) \# be+gir \# (get) \#be+bor\# (cut) (Get this and cut it), it changes into [\#ino\#bigir\#bobor\#], in which /e/ in /be+gir/ and /e/ in [be+bor] change into [i] and [o], respectively. Thus, vowel harmony is not affected by phrase boundaries.

I suppose the study may be of use and of benefit in dialectology, psycholinguistics and phonology as a main and fundamental part of grammar. Furthermore, such a study is of significance to teachers, in that they realize the fact that in addition to intra-linguistic factors, the extra-linguistic factors affect the use of language and the fact that linguistic variations should be taken into account on the whole. Moreover, such a study consolidates the functional and interactional views of language. The study is of use in law as well; judges and lawyers can take advantage of such a study.

The hypothesis of the present survey research is that there is a significant difference between and among different groups of informants' accents regarding their use of vowel harmony (VH).

\section{REVIEW OF LITERATURE}

In spite of the fact that there are a large number of pieces of research devoted to the various aspects of different accents of Persian, unfortunately the study of social aspects of Persian has been ignored by dialectologists. (e.g. as far as the researcher knows a few pieces of research (Modarresi [5], Jahangiri [6], Jahangiri [7], Afkhami and Bagherzadeh Kasmani [8], Bagherzadeh Kasmani [9], Bagherzadeh Kasmani [10], Bagherzadeh Kasmani [11] and Bagherzadeh Kasmani [12] have been conducted on a sociolinguistic study of Modern Persian and the present study is one of these few pieces of research focusing on the sociolinguistic aspects of vowel harmony in Persian.

\section{Methodology}

\section{A. Subject}

A total of 47 informants were interviewed: there are two groups of informants, 27 I.R.I.B. employees (15 male and 12 female) and 20 university students (10 male and 10 female). 
It is worth mentioning that Tehran, the capital and the largest city of Iran, lies on the southern slope of the Alborz Mountains, 63 miles from the Caspian sea, and is located at an altitude of about 3800 feet above sea level. Tehran has a warm summer and a relatively cold winter and all of the subjects (SS) whose accents are under investigation are from this city.

\section{B. Data Collection Procedure}

The data of the present survey research was collected through a randomly classified data collection process, Labovian sociolinguistic interviews; the data, then, was analyzed through the Pearson Chi-square method by means of SPSS. The data was described through cross tabulations and the diagrams as well.

In order to control intervening variables, all informants were chosen from among those informants with almost the same age, the same social class, the same income, the same family income, the same education and all of them are non-mobile, from the same city (Tehran) and with the same native language background, Persian.

The interviews included casual conversations of about three to four hours on different topics that were familiar to the subjects (participants).It is worth mentioning that the interviews continued until all the needed and expected data was collected.

In this study, tokens from the last quarter of the interviews were analyzed because they represents the type of speech that one might find naturally in the speech community under investigation. This was done in line with Labov [13] stating that "the major part of the interview, no matter how casual it may seem on first inspection,must be classed as careful speech."

Furthermore, as Labov [16] contends in a casual and natural situations, a person pays little attention to his speech and uses his more informal and local linguistic forms and in more formal situations his attention is paid to speech more and uses more formal and prestige variants. In this article the author has exerted to study and examine different styles (Free Speech (FS), Reading Sentences (RS), Fast Word Reading (FWR) and Slow Word Reading (SWR)) in terms of the $\mathrm{SS}^{\prime}$ (=students') amount of attention paid to speech.

I followed sociolinguistic research techniques similar to the ones utilized and established in Labov [1], Milroy [2], Eckert [14], Josey [3], Tagliamonte [15] and Oliver Rajan [4].

As you may know, there are inherent problems in the use of impressionistic transcriptions in that the transcriber's expectations can affect what is perceived in the collected interviews .Therefore ,to overcome this problem ,the researcher subjected the interviews to instrumental measurements using Praat.

The linguistic variables/dependent variables are as follows: $/ \mathrm{e} />[\mathrm{i}], / \mathrm{e} />[\mathrm{I}], / \mathrm{a} />[\mathrm{p}], / \mathrm{a} />[\mathrm{a}], / \mathrm{e} />[\mathrm{o}], / \mathrm{o} />[\mathrm{u}], / \mathrm{p} />[\mathrm{u}]$, $/ \mathrm{a} />[\mathrm{o}], / \mathrm{e} />[\mathrm{a}], / \mathrm{a} />[\mathrm{e}], / \mathrm{ow} />[\mathrm{o}], / \mathrm{ow} />[\mathrm{u}], / \mathrm{e} />[\mathrm{e}:]$ and /eI/> [e.].

The expected words on which the vowel harmony $/ \mathrm{e} />[\mathrm{i}]$ and /e/ $>[\mathrm{I}]$ apply are as follows: / $\mathrm{e} \mathrm{e} /$ (six), /bejin/ (sit), /begir/ (get), /telefon/ (telephone), /belit/ (ticket), /sefid/ (white), /beriz/ (pour), /sebil/(mustache), /ardebil/ (the name a city), / Jekpr/ (hunting) and /benevis/ (write); the expected words on which the vowel harmony $/ \mathrm{a} />[\mathrm{p}]$ and $/ \mathrm{a} />[\mathrm{a}]$ apply are as follows: /ta?pm/ (food, dish), /nahpr/ (lunch), /mahpl/ (impossible), /mahpr/ (control) and /bahpr/ (spring); the expected words on which the vowel harmony /e/>[o] applies are as follows: /bebar/ (take), /bebor/ (cut), /bekof/ (kill), /dzelo/ (front), /bexor/ (eat), /begu/ (tell) /bepuf/ (wear), and /bekuf/ (try); the expected words on which the vowel harmony $/ \mathrm{o} />[\mathrm{u}]$ applies are as follows: /boruz/ (show), /rofuze/ (flunked), /foruf/ (selling), /Joluq/ (busy), /tforuk/ (rinkle) and /doruq/ (lie); the expected words on which the vowel harmony $/ \mathrm{b} />[\mathrm{u}]$ applies are as follows: /meidpn/ (square), /peimnn/ (contract), /peimpne/ (unit of measurement), /non/ (bread), /Rpn/ (that), /tehron/ (the name of a city), /irpn/ (our county), xpn/ (tribal chief), /bpm/ (roof), / $\mathrm{bm} /$ (dinner) and /forqun/ (Quran); the expected word on which the vowel harmony /e/>[v] applies is as follows: /bexpb/ (sleep); the expected words on which the vowel harmony /a/> [o] applies are as follows : /mahpr/ (control) and /mahbl/ (impossible); the expected words on which vowel harmony $/ \mathrm{a} />[\mathrm{e}]$ applies are as follows: /tarp $\int /$ (scraping), /bahpr/ (spring), /mahpr/ (control) and /mahpl/ (impossible); the expected word on which the vowel harmony /e/>[a] applies is as follows : /bebar/ (take) and finally, the expected words on which the monophthongization /ow/>[o] and /ow/> [u] apply are as follows: /row Jan/ (light) and /rowqan/ (oil); the expected words on which the monophthongization /eI/>[e:] and /eI/> [e.] apply are as follows: /serl/ (flood) and /xerli/ (very).

It should be noted that the both chosen are just examples in which the vowel harmony occurs.

The afore-mentioned linguistic variables were selected on the basis of the following factors: my own experience and close observation, and the result obtained from a small-scale interviews; many of them are well- known elements among scholars who have studied the Persian phonetic and phonological system; and finally, these phonological features are common in non-standard from.

\section{RESULT}

After collecting the data, by conducting interview and tape recording, as was mentioned, the data were transcribed and then analyzed.

After running a Chi-square test, the following results have been obtained:

After collecting the data, by conducting interview and tape recording, as was mentioned, the data were transcribed and then analyzed.

After running a Chi-square test, the following results have been obtained:

- Comparing the female IRIB employees and female university students' speech regarding their use of vowel harmony $(\mathrm{VH})$, the following results have been observed: there is a significant difference in their use of the linguistic variable /e/ $>[\mathrm{i}]$ in the FWR and SWR styles; in the their use of linguistic variable /e/>[o] in SWR style, in their use of the linguistic variable/o/ $>[\mathrm{u}]$ in FWR style, in the linguistic variable $/ \mathrm{b} />/ \mathrm{u} /$ in all styles under study but in their pronunciation of the rest of the linguistic 
variables under study, there is no significant difference between these two groups of SS.

- Comparing the male IRIB employees and the male university students' speech regarding their use of $\mathrm{VH}$, the following results have been gained: there is a significant difference in their use of the linguistic variable $/ \mathrm{o} />[\mathrm{u}]$ in FWR style and in their pronunciation of the linguistic variable $/ \mathrm{p} />[\mathrm{u}]$ in FS style.

- Comparing the female IRIB and male employees speech regarding their use of $\mathrm{VH}$ in all styles, the following results have been gained: there is a significant difference among the female IRIB employees regarding their use of the linguistic variables $/ \mathrm{e} />[\mathrm{i}], / \mathrm{v} />[\mathrm{u}]$ and $/ \mathrm{ow} />[\mathrm{u}]$, but the male IRIB employees are significantly different in their use of only the linguistic variable $/ \mathrm{p} />[\mathrm{u}]$.

- Comparing the different styles under study in twos regarding the male and female IRIB employees' use of vowel harmony, the following results have been observed:

1) between FS and RS styles, there is a significant difference among the male IRIB employee's use of the variables $/ \mathrm{e} />[\mathrm{i}]$ and $/ \mathrm{p} />[\mathrm{u}]$ and among the female IRIB employees' use of the variable $/ \mathrm{p} />[\mathrm{u}]$

2) between FS and FWR styles, there is a significant difference among the male IRIB employee's use of the variables $/ \mathrm{e} />[\mathrm{i}]$ and $/ \mathrm{p} />[\mathrm{u}]$ and among the female IRIB employees' use of the variable /e/ $>[\mathrm{i}]$ and $/ \mathrm{ow} />[\mathrm{u}]$

3) between FS and FWR styles, there is a significant difference among the male IRIB employee's use of the variable $/ \mathrm{b} />[\mathrm{u}]$ and among the female IRIB employees' use of the variables $/ \mathrm{e} />[\mathrm{i}]$ and $/ \mathrm{p} />[\mathrm{u}]$

4) between FS and FWR styles, between RS and SWR styles, between FWR and SWR styles, there is no significant difference among these SS' speech

- Comparing the male and female university students' speech regarding their use of $\mathrm{VH}$ in all styles, the following results have been obtained:

There is a significant difference among the male university students regarding their use of the linguistic variables $/ \mathrm{b} />[\mathrm{u}]$ and $/ \mathrm{o} />[\mathrm{u}]$, but the female university students are significantly different in their use of only the linguistic variable $/ \mathrm{p} />[\mathrm{u}]$.

- Comparing the different styles under study in twos regarding the male and female university students' use of $\mathrm{VH}$, the following results have been observed:

1) between FS and RS styles, there is a significant difference among the male IRIB university students' use of only the variables $/ \mathrm{p} />[\mathrm{u}]$ and this is true female university students

2) between FS and FWR styles; between FS and SWR styles; and between FWR and SWR styles; between RS and SWR styles, and between FWR and SWR styles there is no significant difference between these SS' speech, except in case of the use of the linguistic variable /p/> [u], there is a significant difference between FS and FWR styles, and FS and SWR styles in both male and female university students' speech. And, between RS and FWR styles, there is a significant difference among the male university students' speech

What follows are two figures summarizing the percentage of the use of $\mathrm{VH}$ by gender and occupation:

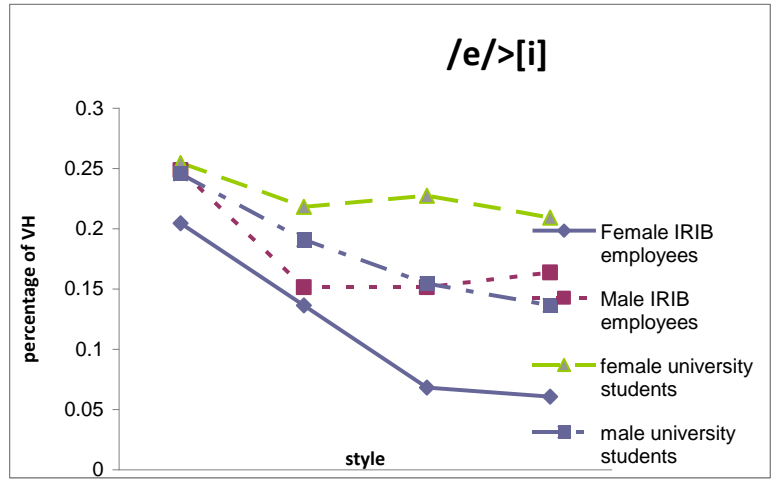

Fig. 1. The percentage of the use of $\mathrm{VH} / \mathrm{e} />[\mathrm{i}]$ by gender and occupation.

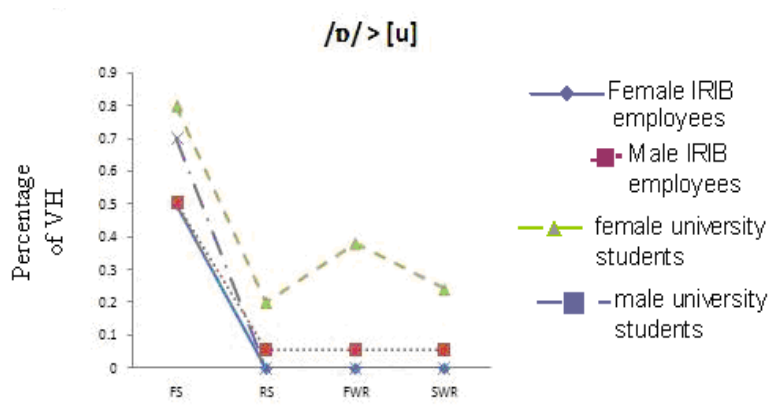

Fig. 2. The percentage of the use of $\mathrm{VH} / \mathrm{a} />[\mathrm{D}]$ by gender and occupation.

Fig. 1 shows the effect of the amount of attention paid to speech confirming the idea that the more amount of attention is paid to speech, the less informal and less natural speech and prestige variants emerge and this can be one of the factors by which one can explain "change in progress", and explain why changes are in progress. Moreover, Fig. 2 clearly demonstrates another factor giving rise to a change in the use of VH: since the use of $\mathrm{VH}$ on /npn/ leading to [nun], on /Rpn/ resulting in [?un] and the other variants of the variable $/ \mathrm{b} />[\mathrm{u}]$ are prestige variants, female people use more $\mathrm{VH}$ on these than male ones but in other cases when the formal variants are more prestige ones, they do the reverse, they use the more formal variants. This also shows that female people tend to use more prestige variants than male ones leading to a change in language in general (and in the use of $\mathrm{VH}$ in particular). Furthermore, this shows that "prestige" affects the use of VH as well.

\section{DISCUSSION}

Regarding the results obtained via analyzing the data, one can claim that "gender" can be considered as a factor for linguistic change. The results show that among the different styles under study, there is $21 \%$ significant variation in female IRIB employees and only $7 \%$ in male IRIB employees' use of VH confirming the intrinsic variability acceptance theory.

After analyzing the obtained data, a number of very important points seem to be worth mentioning. First, comparing the female IRIB employees and female university students, the former SS use more formal variants. This may be due to the fact that the former SS are under the influence of mass media more than the latter SS. This shows that formal setting affects the use of $\mathrm{VH}$.

Second, regarding the obtained results, there is a significant difference between female university students and female 
IRIB employees in their pronunciation of the most variant variable under study /e/>[i], but this is not true of their male counterparts. This clearly shows that in a higher level of pattern, female and males' speech is systematically different confirming the impact of gender on the use of $\mathrm{VH}$, and hence the theory of orderly heterogeneity.

Third, the analysis of results shows that there is a significant difference among the female university students' use of $7 \%$ of the variables while there is a significant difference among the male university students' use of $14 \%$ of the variables. This shows that there are more variations in male university students' use of $\mathrm{VH}$ in comparison with the female university students' use of VH. In addition, this shows that there is a little variation among both female and male university students' use of VH. On the contrary, the analysis of the results shows that there is a significant difference among female IRIB employee's use of $21 \%$ of the variables whereas there is a significant difference among male IRIB employees' use of $7 \%$ of the variables. This shows that setting (being in a university and working in a broadcasting center like IRIB center) may affect the use of $\mathrm{VH}$ and is considered as a factor for linguistic change as well.

Fourth, the analysis of the results shows that the more formal the style becomes, the less use of $\mathrm{VH}$ occurs. The mean of the percentage of the use of $\mathrm{VH}$ in $47 \mathrm{SS}^{\prime}$ speech in FS style is $21.59 \%$, in RS style is $12.71 \%$, in FWR style is $10.44 \%$ and in SWR style is $8.72 \%$. This shows that style affects the use of $\mathrm{VH}$ in Persian: the more the mount of attention is paid to speech, the less VH appears in SS' speech.

Fifth, the obtained results confirm the findings in Bagherzadeh Kasmani [9] "the variants which have a semantic rivel and phonetic rival in the colloquial speech do not undergo vowel harmony. For example, the variant [bekuf] (try) has three rivals: [kufe $\left.\int \mathrm{kon}\right]$, [talp $\left.\int \mathrm{kon}\right]$ and [sar kon] because of which the frequency of [bekuf] decreases and this impedes the use of vowel harmony; and , rarely do [bom], [ $\mathrm{pm}],[\mathrm{xpn}]$ and [forqpn] undergo vowel raising because they have phonetic rivals [bum], [Jum], [xun] and [forqun]. As another example, the variant [peImpn] (contract) does not undergo vowel raising because it has two semantic rivals: [qowl] and [qarprdpd] in colloquial speech, but [peimpne] (unit of measurement) undergoes vowel raising (some of the informants have used vowel raising on this item) because it has no semantic rivals in the colloquial speech", and hence confirming the rule of avoidance of homonymy introduced firstly in aforementioned reference.

Sixth, the obtained results show that deletion of a syllable and the appearance of a syllable between the two vowels to be assimilated impedes the use of vowel harmony. This is why none of the informants produced the following forms:
1) *[tolfun] (telephone)
6) *[tolefun]
11) $*$ [bine $\int$ in $]$
2) $*$ [tolfon]
7) *[tulfan]
12) $*$ [bı n $\mathrm{Sin}]$
3) *[tolefun]
8) *[bine $\int$ in $]($ sit $\left.) 13\right) *\left[\right.$ bin $\int$ in $]$
4) $*\left[\operatorname{bin} \int 1 \mathrm{n}\right]$
9) $*$ [bı nvis $]$
5) *[binvis]
10) $*$ [b nevis $]$

But some of them produced the following variants:
1) [telefon]
5) [bene-in] 9) [benvis]
2) [telfon]
6) [bifin] 10) [benivis]

\section{3) [tilifon] 7) [be $\mathrm{in}]$ \\ 4) [benfin] 8) [benevis]}

Two linguistic facts are observed from the above data: 1) the data 1,2,5,8,9,10,11 and 13 show that delition of a syllable resulting a closed syllable impedes the use of vowel harmony but the data 20 shows that delition of a syllable resulting in an open syllable does not prevent vowel harmony from occuring; 2) the data 3,4,6,7,12 and 14 demonstrate that the appearance of a syllable between the two vowels to be assimilated impedes the use of vowel harmony.

These results show that in addition to the afore-mentioned non-linguistic factors, linguistic factors also affect the use of vowel harmony.

Finally, by running multivariate $\log$ linear, it has been demonstrated that both gender and style affect the use of $\mathrm{VH}$ in Persian but gender has more effects on the use of $\mathrm{VH}$ and hence confirms the idea that orderly heterogeneity characterizes natural language, and any adequate description or theory of language must incorporate this variation.

\section{CONCLUSION}

The conclusion of the research is that the shape of linguistic behavior changes rapidly as the speaker's social position (here gender) changes. Close studies of the social context in which language is used show that many elements of linguistic structure are involved in systematic variation which reflects both temporal change and extra-linguistic social processes.

Furthermore, the study shows that in addition to intra-linguistic factors, extra-linguistic factors (such as gender, occupation, prestige, the frequency of occurrence of the linguist elements and exposure to mass media) also affect the use of vowel harmony.

\section{REFERENCES}

[1] W. Labov, "The social stratification of english in New York city," Washington: Center for Applied Linguistics, 1966.

[2] M. Leslie, Language and Networks (2nd ed.), Oxford: Blackwell, 1987.

[3] M. Josey, "A sociolinguistic study of phonetic variation and change on the island of MARTH's vineyard," New York University, Ph.D. Thesis, 2004.

[4] J. O. Rajan, "Mobility and its effects on vowel rising in the coffee zone of Puerto Rico," in Selected Proceedings of the Third Workshop on Spanish Sociolinguistics, J. Holmquist, A. Lorenziu, and L. Sayahi, Eds. Somerwille, MA: Cascadilla Proceedings Project, pp. 44-52, 2007.

[5] Y. Modarresi, "A sociolinguistic analysis of modern persian," $\mathrm{PhD}$ Dissertation, University of Kansas, 1978.

[6] N. Jahangiri, "A sociolinguistic study of tehrani persian," London University, PhD Thesis, 1980

[7] N. Jahangiri, A Sociolinguistic Study of Tehrani Persian, Tokyo: Tokyo Press Co. Ld., 2000.

[8] A. Afkhami and M. B. kasmani, "A sociolinguistic analysis of vowel harmony in Persian," Barrasi-ye dzome?eh fenvxti-ye hamphangi-ye vpkehi dar zabpn-e farsi, Tehran: Tehran College of Literature and Humanities 58 University Press, vol. 1386, 2007, pp. 1-17.

[9] M. B. Kasmani, "A socio-linguistic study of vowel harmony in Persian (different age groups use of vowel harmony perspective)," in International Proceedings of Economics Development and Research, ed., Chen Dan, Ed. Singapore: IACSIT Press, vol. 26, pp. 359-366, 2011.

[10] M. B. Kasmani, "Occupation and its effects on vowel harmony in Persian (A sociolinguistic study)," presented at the International Akdeniz Language Studies Conference, Antalya, turkey, May 9-12, 2012.

[11] M. B. Kasmani, "A sociolinguistic study of vowel harmony in Persian (different accents perspective)," International Journal of Social 
Sciences and Humanity, vol. 2, November 2012, pp. 525-528, Singapore: IACSIT Press.

[12] M. B. Kasmani, "Education and its effects on vowel harmony: A sociolinguistic study," presented of $2^{\text {nd }}$ International Conference on Linguistics, Literature and Culture, Penang, Malaysia, 7-9 November, 2012.

[13] W. Labov, "Principles of linguistic change, volume: Internal factors," Oxford: Blackwell, vol. 9, pp. 157, 1994

[14] P. Eckert, "Variation, convention and social meaning," presented at the Annual Meeting of the Linguistic Society of America, Oakland CA, 2005.

[15] S. A. Tagliamonte, Analyzing Sociolinguistic Variation, Cambridge: Cambridge University Press, 2007.

[16] W. Labov, Sociolinguistic Patterns, University of Philadelphia, Pennsylvania Press, Oxford: Basil Blackwell, 1972, pp. 208-209.

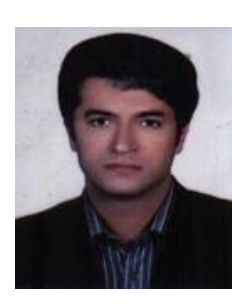

Morad Bagherzadeh Kasmani was born in Babol, Mazandaran province, Iran. He received his B.A. degree in English literature from Shahid Bahonar university in Kerman of Iran in 1989 and the M.A. degree in general linguistics from Shiraz university of Iran in 1997. Moreover, he got his Ph.D. from Tehran university of Iran in 2009. He has been teaching for 17 years at Islamic Azad University, Chalous branch, Iran as an academy member, and is currently an assistant professor. He has had some articles and books published five of which are cited in this article. His areas of interest in linguistics are sociolinguistic variation, phonology and morphology. He is a member of Linguistic Society of Iran (LSI) and TEllSI. 